Revista Iberoamericana, Vol. LXVIII, Núm. 201, Octubre-Diciembre 2002, 969-979

\title{
EMBESTIDA A LA BURGUESÍA: HUMOR, PARODIA Y SÁTIRA EN LOS ÚLTIMOS RELATOS DE SILVINA OCAMPO
}

\author{
POR
}

Hiram Aldarondo

Temple University

No cabe duda que la obra cuentística de Silvina Ocampo parece finalmente cobrar una gradual y merecida importancia por parte de la crítica literaria. Su obra ha estimulado en el pasado excelentes lecturas acerca de materias tan variadas como la desmitificación infantil y la crueldad (Molloy, Meehan, Balderston), lo fantástico y la perspectiva feminista (Fox-Lockert, Klingenberg), el erotismo (Araújo) y las diferentes estrategias narrativas (Ferreira-Pinto, Tomassini). Sin embargo, a pesar de esta creciente y paulatina muestra de estudios, muy poco se ha indagado con profundidad acerca del humor sagaz y sutil que campea y, en muchas ocasiones, estructura sus relatos. Si bien el humor no ha pasado inadvertido para los críticos, sigue siendo objeto de interpretaciones generales y complementarias. ${ }^{1}$ La propia escritora argentina en una de las escasas entrevistas que concedió en vida, se queja ante su interlocutora de esta falta de reconocimiento humorístico: "Me gustaría que me hicieran una antología de cuentos humorísticos, vos sos una de las pocas personas que los ha tomado en cuenta” (Ulla 103).

Nuestra investigación tratará precisamente de analizar parte de ese punto de vista humorístico en sus últimas tres colecciones de cuentos, quizás las menos estudiadas hasta la fecha: Los días de la noche (1970), Y así sucesivamente (1987) y Cornelia frente al espejo (1988). En esta ocasión nos limitaremos a examinar el humor afiliado a la sátira con vistas al desenmascaramiento y desmitificación de ciertas actitudes burguesas y de marcados estereotipos sociales. Al mismo tiempo plantearemos que algunos de sus relatos se presentan en un diálogo intertextual con otros géneros literarios, parodiando de paso los intertextos en cuestión. ${ }^{2}$

Linda Hutcheon al diferenciar la sátira de la parodia señala que la primera es siempre cómica y va encaminada en dirección a una realidad fuera del contexto literario,

\footnotetext{
${ }^{1}$ A pesar que los libros recientes de Graciela Tomassini y Patricia N. Klingenberg han tomado en consideración para sus acertados estudios el tema del humor, hasta la fecha no he hallado ningún trabajo enfocado y detenido exclusivamente en las estrategias humorísticas de Ocampo.

${ }^{2}$ Este estudio pertenece a una investigación mucho más amplia sobre las distintas estrategias humorísticas empleadas en la obra de Ocampo. Aunque en esta ocasión me limito al humor satírico y paródico, el humor e ingenio en Ocampo tiene varias ramificaciones y tonalidades. Por lo regular no está necesariamente asociado al típico chiste alegre o festivo, sino más bien a uno que puede llegar a ser obscuro, nebuloso, grotesco, incluso confuso y problemático en ciertas ocasiones. De ahí la mentada "crueldad" atribuida a una parte de su narrativa corta.
} 
privilegiando, entre otras cosas, la exageración caricaturesca con el propósito de acentuar su mensaje crítico-moralizador (Hutcheon 43-44). Para ello, es imperativo un blanco de ataque (idea, persona, institución o practica cultural) delineado y manifestado de alguna manera en el discurso textual (Test 29). Elzbieta Sklodowska coincide en parte con Hutcheon al enfatizar el aspecto intratextual de la parodia, mientras señala "que la sátira se dirige hacia una realidad extraliteraria” (Sklodowska 12). Para los efectos de este estudio, compartimos entonces la noción de intertextualidad asignada a la parodia y su estructura fundamentalmente bi-textual y dialógica como una diferencia fundamental que la separa de la sátira. Sin embargo, coincidimos con Sklodowska en que "la relación paródica entre el texto y el pre-texto se caracteriza por una distancia irónica que puede ser matizada a través de una variedad de recursos y producir toda una gama de impresiones subjetivas”, incluyendo un ethos extratextual y satírico (14). En los cuentos escogidos nos proponemos evidenciar cómo la parodia sutil de algunos pre-textos se emplea para apoyar la sátira extratextual, la cual domina y manipula los relatos. En última instancia, el humor y la sátira, apoyados en algunos casos por la parodia de pre-textos, van a ir encaminados a desenmascarar una moral pequeño-burguesa caracterizada como trivial y absurda. La sátira, sustentada por la caricatura y la hipérbole, pretende además propiciar el reconocimiento y, como consecuencia inmediata, el cambio. De esta manera, esta rama de la cuentística de Ocampo se exhibe como el aspecto comprometido y desengañado de una reflexión grave sobre la moral burguesa a través de una línea de ejemplos que ilustran su naturaleza. ${ }^{3}$

LOS EXCESOS Y ABSURDOS DEL MUNDO BURGUÉS

El mundo de la alta burguesía y sus marcadas extravagancias quedará caricaturizado en uno de los cuentos más originales de esta última parte de la producción de Ocampo. "La música de la lluvia”, publicado en su libro Y así sucesivamente, muestra las acciones desproporcionadas que lleva a cabo un virtuoso pianista ante un grupo selecto de personas pudientes, a la vez que retrata impunemente al grupo social satirizado. ${ }^{4}$ El protagonista resulta risible en la medida en que su excentricidad de carácter se destaca sobre una situación de normalidad, representada por el resto de los personajes. Su llegada a la casa en un inusitado coche de caballos, en vez de un automóvil, marca el tono extravagante y caprichoso del concertista. A partir de ese momento, la bola de nieve, especie de adagio narrativo, irá in crescendo. Luego de saludar a la concurrencia con un brusco movimiento de cabeza que lo deja completamente despeinado, el célebre músico/payaso se quita los

\footnotetext{
${ }^{3}$ Esta reflexión no sólo consiste en pensamiento sino que también es experiencia vivida. La familia de Ocampo perteneció a la más antigua aristocracia argentina, de legendaria opulencia y de costumbres extremadamente refinadas. Victoria Ocampo, hermana mayor de la escritora, da constancia de lo anteriormente expuesto en su extensa y notoria biografía.

${ }^{4}$ La sátira del mundo burgués aparece retratada con frecuencia en previas colecciones de cuentos. En "Las fotografías", una de las piezas de la serie La furia (1959), lo que pretende ser una celebración familiar pequeño-burguesa organizada para festejar el cumpleaños y el regreso de una niña paralítica, termina siendo la causa de su muerte. La descripción de la antifiesta se convierte en representación perversa del estereotipo.
} 
zapatos, las medias, y procede a internarse en las profundidades del piano, examinado como un médico a un enfermo, el instrumento de su vehemencia. Acto seguido, ajusta su taburete, se contempla los pies descalzos un par de veces y, de forma imprevista, empieza a tocar "con el dedo gordo del pie. Las notas se sucedían con un staccato originalísimo" (30). El dueño de la casa ante tanto capricho, y para no preocupar a los atónitos invitados, había exclamado súbitamente: “Es un excéntrico” (29). Una vez establecidos los parámetros de su locura, todo el mundo permanece imperturbable y sosegado.

Queda claro que el cuento viene a representar una burla del mundo del arte y de la música que celebra todo lo novedoso. ${ }^{5}$ Si la caricatura no es otra cosa que la exageración de un vicio, según estudiosos del tema como Pirandello y Koestler, entre otros, ésta alcanza su mayor grado posible en el tratamiento que la narradora-testigo le va dando a los gestos mecánicos y maniáticos del protagonista. La estrategia caricaturesca y el tono burlón surten el efecto humorístico en la medida en que el lector comparte el guiño que le transmite la narradora. La exposición hiperbólica del estereotipo tiene como propósito la revelación irónica. La ironía se revela por medio del contraste entre lo que el pianista se considera a sí mismo y lo que el lector infiere de él: él se considera un virtuoso, el lector lo ve como un payaso.

A pesar de que la falsedad de sus posturas es evidente, la representación del pianista reviste una solemnidad tan sobrecargada que termina cautivando al público de la gala musical-circense. La deformación caricaturesca entonces no sólo va para aquellos que protegidos bajo la sombra de la "genialidad" llevan a cabo todo tipo de extravagancias y desvaríos, sino también para ese público fanático que patrocina y apoya tan insólitos comportamientos. Los comentarios disparatados y ridículos de los invitados ejemplifican la marcada pretensión deformadora. La madre del pianista en vez de sorprenderse que su hijo tocara exclusivamente con el dedo gordo del pie, justifica su selección a los invitados, y explica que no hubo forma de convencerlo para que tocara con el resto de los dedos de los pies (en vez de los dedos de las manos). Otro de los invitados señala que sólo los “inválidos" recurren a tales talentos, sin embargo, éste no era el caso del referido pianista, todo el mundo lo había visto llegar caminado y saludando con marcado movimiento corporal. El consenso general, no obstante, parece claro: "no hay que contrariar a los genios" (32).

El papel de correctivo social desempeñado por el humor, reside en su capacidad para revelar estos absurdos del hombre. El tono ridiculizante del cuento hacia el grupo satirizado es aun más evidente cuando la narradora describe cómo al llegar y sentarse los invitados, era muy difícil que éstos volvieran a pararse de sus asientos, los sillones eran “demasiados cómodos, tan cómodos que después de un rato era difícil para algunas personas incorporarse, de modo que la actitud que tomaron sugería la permanencia” (28). La crítica esta vez va dirigida hacia esa rigidez mecánica del grupo social, enviciada por una pereza persistente. ${ }^{6}$ Hacia el final del cuento ya nadie prestaba atención al músico, la

\footnotetext{
${ }^{5}$ La burla puede muy bien abarcar otras ramas del arte, incluyendo la propia literatura. En este caso, quedarían expuestos y ridiculizados aquellos falsos escritores que reciben el apoyo incondicional de lectores ingenuos que celebran igualmente todo tipo de excentricidad.

${ }^{6}$ Esa exagerada comodidad y pereza de la clase burguesa es tema constante en la cuentística de Ocampo. Un caso concreto se da en uno de los cuentos más conocidos de la escritora: "El vestido
} 
lluvia que golpeaba los cristales y la conversación de los invitados dificultaban toda comunicación. El insólito pianista decide entonces entrar nuevamente a las entrañas del piano, consiguiendo de esta manera "la total desafinación del instrumento”. Es así como el concierto acuático estalla en una orgía estrambótica de ruidos inconexos y antirrítmicos. En vez de armonía, consonancia y acordes musicales, los invitados terminan escuchando y halagando un retumbo desafinado de sonidos dispares. Allí "no se reconocía ni Carnaval, de Schumann, ni Jardín bajo la lluvia, de Debussy, ni Juegos de agua, de Ravel” (37). Piezas musicales que funcionan como reflejos del cuento, juego paródico de estridencias desmesuradas. El adagio narrativo termina con la despedida del músico acompañado de su madre, con la sugerencia de que el famoso concertista sea con toda probabilidad un "niño precoz", después de todo toca "el piano como un niño de cinco años” (38). Su edad permanece en secreto, ya que el excéntrico pianista se quita "la poquita edad que tiene”. Sin embargo, el piano de juguete que el dueño de la casa le regala al músico, insinúa no sólo lo expuesto anteriormente, sino el doble caricaturesco y el juego lúdico implícito.

La comicidad en “La música de la lluvia” no nace solamente a nivel de los personajes o de la pretendida burla social, sino también de una serie de juegos intertextuales. Es así como el cuento revela, además del palimpsesto musical, una parodia sutil e implícita de las formas del discurso romántico y del archifamoso relato de horror. La narradora por ejemplo, en su descripción inicial del dueño de la casa, se burla de la pose artificial que éste asume junto a una ventana: "Estaba tan habituado en su ilusión a que lo retrataran que adoptó esa postura romántica” (28). Por otro lado, refuerza la atmósfera de misterio que rodea al inusual pianista, con la descripción de una noche de tormenta donde abundan continuos relámpagos y truenos, elementos que recuerdan a los fantasmagóricos cuentos de terror. De hecho, la entrada del concertista al salón de la casa está precedida por la trillada iluminación de un relámpago. La manipulación y desvalorización intertextual es, sin embargo, parte de una estrategia mayor que emplea la imitación exagerada (incluyendo la parodia del discurso cliché) para crear un efecto humorístico que retrate un comportamiento social pueril. La sutil parodia, complementa la sátira social, estrategia no del todo ajena a los escritores que hacen uso de ella (Sklodowska 170-71). Es decir, la parodia del discurso romántico-terrorífico incrementa la función burlesca de la sátira, al añadir una literatura considerada como extravagante y estereotipada a la pretendida trivialidad y extravagancia del mundo burgués.

CARicatura DEL ESTEREOTIPO FEMENINO BURGUÉS

En comparación con otras escritoras contemporáneas, Ocampo no sólo lleva a cabo una acusación del personaje masculino burgués y su mundo, sino que también censura de la misma manera la inacción e ineptitud de las mujeres burguesas que contribuyen con sus acciones y comportamientos a perpetuar ciertos estereotipos sociales. El espacio de la mujer burguesa aparece representado por figuras frívolas y superficiales que tienden a la

de terciopelo”, publicado en la colección La furia . En él, la dueña de la casa, con marcada arrogancia egocéntrica, llega al colmo de la pereza cuando le declara sin rodeos a su modista: "¡Si alguien se probara los vestidos por mí, qué feliz sería! Me cansa tanto” (144). 
mecanización de sus actos. En estos cuentos, la alusión a ese mundo femenino y burgués se exhibe en consideraciones claramente recurrentes, como la incapacidad de estos personajes de desafiar y subvertir las reglas. Esto podría ser interpretado como una presentación paradójica y polémica, sobre todo desde la perspectiva feminista moderna, sin embargo, estos personajes no componen en lo más mínimo el variado y diverso mundo femino-céntrico de la autora. ${ }^{7}$ Por otra parte, sospechamos que el uso de estereotipos femeninos es una especie de contraestrategia. Ocampo pretende no sólo reírse primero de ella misma y su clase social, sino que al mismo tiempo expone y provoca a aquellas mujeres que siguiendo subordinadamente el orden dominante, se convierten en cómplices y promotoras del mismo. La sátira irá dirigida entonces específicamente a cierto tipo de mujer burguesa, allí el estereotipo quedará atrapado en una exageración caricaturesca provocando una distancia crítica desde la cual el lector se reconoce en una especie de espejo reflector.

El cuento “Las esclavas de las criadas”, publicado en su libro Los días de la noche, es quizás, como se puede inferir por el título irónico del cuento, un ejemplo cabal de la técnica de inversión y de lo expuesto anteriormente. Elaborado como una crítica mordaz de la desesperación burguesa por la comodidad y la servidumbre, el relato enfoca la atención desmedida e interesada que unas damas de sociedad le dan a una eficiente criada. ${ }^{8}$ La historia en concreto gira alrededor de las innumerables visitas efectuadas a la casa de la señora de Bersi, no para verla a ella o enterarse de su precaria y delicada salud, sino para tratar de hablar a escondidas con su criada Herminia y proponerle seductoras ofertas de trabajo. Las inoportunas ofertas de empleo le llegan a "la perla" de Herminia junto al lecho convaleciente de su señora. Sin embargo, lejos de beneficiar a la criada, la perjudica de sobremanera:

Herminia, cuando muera la señora de Bersi, Dios no lo quiera, pero todo puede suceder, a veces me pregunto si no vendría usted a trabajar a mi casa. Tiene un cuarto para usted sola, puede salir todos los domingos y días de fiesta, se entiende. La trataré como una hija, y, después, créame, no sería tanta la tarea que usted tendría que hacer; menos que aquí [...] Usted es fuerte, pero nunca se sabe si conviene hacer tantos esfuerzos. En casa, es claro, tendría que hacer un poquito de costura, de lavado, de cocina, de limpieza de patios, de planchado, también tendría que sacar al perro a pasear, tres veces por día, y bañarlo

\footnotetext{
${ }^{7}$ La obra de Ocampo ofrece una verdadera galería de personajes femeninos, creando un efecto de abanico entre los variados tipos de existencia que estas mismas mujeres representan. El estereotipo femenino no es siempre llevado a la exageración caricaturesca con fines burlescos, en muchas otras ocasiones se lleva a cabo una reversión paródica, subversiva y reinvindicativa del estereotipo con la intención de desacralizar roles y comportamientos prefijados, como sucede en los relatos "El automóvil” ( $Y$ así sucesivamente) y "Jardín de infierno" (Cornelia frente al espejo), entre otros. De hecho, la inversión como técnica narrativa constituye una de las rasgos más notables en la escritura de Ocampo.

${ }^{8}$ Esta dependencia burguesa de la servidumbre (criadas, cocineros, porteros, planchadoras, enfermeros y modistas) aparece ironizada y de forma frecuente en la obra de Ocampo. En el cuento "El crimen perfecto" de la serie Las invitadas (1961), será un cocinero el que ejercerá su oficio con marcada superioridad, la cocina será el espacio donde asumirá absoluto dominio no sólo de las comidas, sino también de los gastos de la despensa.
} 
y secarlo, cepillarlo una vez por semana, pero son todas cositas livianas que se hacen en un minuto. En una palabra, no tendría nada que hacer. (62-63)

La sátira del fragmento se da al identificar a la compradora con la pereza, la explotación, el oportunismo, la falsedad y la manipulación hipócritamente disfrazada de una clase social. En efecto, la representación satírica se presenta como entidades de un cosmos unido por una acusación persistente: la hipocresía de clase. Lo risible y absurdo de la situación se da cuando la conquista y competencia por la criada se acrecienta, convirtiendo el proceso en una especie de parodia de las subastas de objetos valiosos llevadas a cabo en el mundo burgués. La deshumanización de Herminia y su pronta cosificación, la convierten súbitamente en artículo codiciado de remate. Las ofertas de compra son cada más llamativas y generosas, van desde viajes de "veraneo al borde del mar” y estadías en Bariloche durante el invierno, hasta viajes a Europa y asistencia a conciertos particulares en el "conservatorio de Chicago". El efecto abrumador de estas actuaciones degradantes logran el efecto humorístico. La saturación del estereotipo y su representación ilimitada se logran mediante el libre desenvolvimiento de su actuación, es decir, dejando que el encarnado trompo dé vueltas independientemente de su cordel.

Toda esta representación se lleva a cabo a pesar de la condición delicada de la dueña de la casa. En su falsa hipocresía, las compradoras no sólo ignoran a la moribunda, sino que tratan de persuadir a los doctores para “acortar” su “vía crucis”: “¿No le parece, doctor, que prolongar la vida de una señora que sufre tanto es un ... una falta de humanidad?”; "Yo, en lugar de ella, preferiría realmente que se me diera algo para terminar de una vez con la vida” (65). "La falta de humanidad” se convierte claramente, por la intención de quienes la emiten, en franca ironía del cuento. Ocampo, al exponer estos mecanismos de manipulación en medio de casos extremos de sufrimiento, demuestra cuán saturada se encuentra la alta burguesía de su propia ideología de dominación y control. Esta falta de compasión e hipocresía será vengada por la propia criada, quien logra mediante poderes ocultos que el hijo avaro de la señora y cada una de sus compradoras mueran de forma misteriosa e inexplicable. Al final Herminia permanece fielmente al lado de su "ama”, quien parece recuperarse y vivir una prolongada existencia gracias a los cuidados particulares que le brinda su esmerada sirvienta.

Queda claro, sin embargo, que la burla mordaz va hacia esa clase deshumanizada e interconectada a los sistemas de opresión que ha llegado a convertirse en "esclavas de criadas”. La inversión de papeles genera el efecto cómico tan pronto el lector percibe como las esclavas (amas de casa) viven en torno a sus amas (las sirvientas), y como sobre ellas gira su vida sin sentido. Sus diálogos sociales confirman esa vida mecanizada y trivial: "la muchacha se me fue"; "la muchacha que tengo es malísima"; "estoy buscando una muchacha pero con recomendaciones” (61). En la dependencia y búsqueda de ese objeto perseguido, malgastan y derrochan esa existencia rutinaria, convirtiéndose en prisioneras del propio objeto anhelado. En este cuadro degradado de la vida burguesa, el humor y su catarsis facilita la sonrisa del reconocimiento en el lector, quien advierte la inversión de valores y la crítica implícita a la sociedad moderna inmersa en conductas y automatismos del esnob. 
Un caso semejante se da en el sugerente cuento “Los celosos”, publicado en su última serie Cornelia frente al espejo. Aquí la frivolidad y la trivialidad se acentúan más allá de la caricatura para llevar a cabo una crítica severa a ese código burgués-patriarcal que impone y promueve en la mujer utopías particulares de belleza. En el relato, el marido "de la mujer más coqueta del mundo”, vive una farsa irónica que raya en lo hiperbólico. La estrategia humorística del cuento está basada en una especie de sistema irónico de ruptura. Uno de los sistemas sería la concepción de belleza que el marido tiene de su mujer burguesa (A), sin embargo, la ruptura del sistema se da con el descubrimiento de que la esposa es todo lo contrario de lo que su marido piensa (B). La representación de las incongruencias entre la imagen que tiene el marido y los conocimientos que tiene tanto el narrador como el lector, constituyen la quiebra del sistema previamente convenido y por ende la salida desaforada del humor. Wayne C. Booth llama a este tipo de ironía, “ironía dramática”, ya que "siempre depende estrictamente de algún conocimiento que el lector o el espectador sabe acerca de la situación del personaje, pero que el propio personaje ignora” (255). ${ }^{9}$

La percepción que tiene el engañado marido de su esposa (sistema A) denota de inmediato una concepción femenina configurada y promocionada por parámetros androcéntricos:

Sos el tipo de mujer moderna que tiene aceptación en todos los círculos. Alta, de ojos celestes, de boca sensual, de labios gruesos, de cabellos ondulados, brillantes, que forman una cabeza que parece un soufflé, de ésos bien dorados, que despiertan mi alma golosa. ¡La pucha que me das miedo! Si fueras una enana o si tuvieras ojos negros, o el pelo pegoteado, mal peinado y las pestañas descoloridas... o si fueras ronca, ahí nomás; si no tuvieras esa vocesita de paloma. A veces me dan ganas de querer a una mujer así ¿̇sabes? Una mujer que fuera lo contrario de lo que sos. (126)

La descripción altamente gastronómica denota no sólo una configuración patriarcal de la mujer, sino también una saturación implícita de elementos estéticos patrocinados por la cultura popular y comercial (industria de cosméticos, revistas especializadas) que en última instancia funcionan como forma de control social sobre la mujer.

La esposa, sin embargo, lejos de poseer todos los atributos físicos expuestos por su marido, esconde a través de un travestismo perenne, su verdadero rostro. Las máscaras y falsos aditivos resultan ser numerosos: lleva siempre puestos lentes de contactos celestes que ocultan unos ojos miopes y opacos, sus pestañas son más bien desechables, tiene

\footnotetext{
${ }^{9}$ La traducción al español es mía. Esta idea es también compartida por Bergson, quien señala que el comediante es una especie de personaje inconsciente que se hace irreconocible para sí mismo siendo totalmente reconocible para el resto del mundo (Bergson 13). Por otro lado, la ironía dramática funciona a la par con la ironía del enunciado. El narrador del cuento no puede evitar el juego irónico. Al señalar, por ejemplo, las supuestas cualidades deportivas de Irma, refiere como en varias oportunidades ésta se destacó como nadadora y como “amazona”, para luego añadir acto seguido que nadaba con salvavidas, y su caballo "Arisco" era más bien intoxicado con narcóticos por su cuidador para obtener una "mansedumbre perfecta” (124). Esta mirada irónica de los narradores de Ocampo (con sus múltiples máscaras) es — según críticos como Molloy, Balderston y Tomassini, entre otros, y coincido totalmente con ellos_ otra de las características fundamentales de la escritura de Ocampo.
} 
labios microscópicos que se agranda con delineadores labiales, se tiñe su descolorido cabello y usa un sinnúmero de jopos y postizos para abultar su escasa cabellera. Más aún, es "muy bajita (hasta dijeron que era enana), se mandó hacer unos zuecos con plataformas que medían veinte centímetros de alto”, con lo cual consiguió en poco tiempo “que su marido se creyera más bajo que ella” (124). El discurso estereotipado e hiperbólico continúa desprovisto y carente de frenos. La esposa no sólo dormía con todo el maquillaje, las uñas falsas, los zuecos y todos los postizos, sino que la posición que debía adoptar para no deshacer su elaborado peinado era "sumamente forzada e incómoda", con lo cual “consiguió en poco tiempo una seria desviación de la columna vertebral” (124).

El humor tragicómico en el cuento va más allá de un simple juego de máscaras, éste le sirve a la escritora como arma para exponer precisamente ese código ideológico imperante que pretende imponer a la mujer rituales de belleza con el fin de transformarla en objeto codiciado del hombre, destinatario final de las transformaciones. ${ }^{10}$ Los sacrificios autoinfligidos a los que se somete Irma Peinate (el apellido la define y representa) tienen el objetivo de alcanzar y retener unos (sin)valores codificados por la sociedad machista y burguesa. La cosificación de la protagonista y su reducción a una simple muñeca de cambiantes vestiduras, pertenecen a una imposición social de difícil escapatoria. De ahí que el dardo irónico al final no vaya dirigido solamente a la mujer-muñeca, sino también al engañado marido que no ve o se niega a ver la realidad evidente. En efecto, el marido no sólo desconoce la apariencia física real de su mujer, sino que además sufre irónicamente de unos celos infundados que lo atormentan. El lector sabe que las salidas secretas de Irma no tienen que ver con encuentros amorosos extramatrimoniales, sino con visitas al odontólogo para reponer de emergencia un diente que había perdido en un accidente de caballo. A pesar de este conocimiento, nada prepara al lector para la amena sorpresa que le espera al final. El inseguro marido, convencido ya del adulterio de su mujer, un día la espía y la sorprende saliendo sospechosamente del consultorio del dentista. En un arrebato de cólera desenfrenado "blandió el paraguas y, al asestar a Irma un golpe en la cabeza, le rompió el premolar recién colocado y simultáneamente se le cayeron los cristales de contacto, las pestañas, los postizos de su peinado; las sandalias altas fueron a parar debajo de un automóvil” (127). Ante el desarme, ante la salida desenfrenada de rellenos y postizos, el marido engañado dispara imprevistamente: "Discúlpeme, señora. La confundí. Creí que era mi esposa... Ojalá fuese como usted; no sufriría tanto como estoy sufriendo” (128).

El humor en este inesperado final se debe a que los nuevos conocimientos dan lugar al establecimiento de un sistema dentro del cual se espera una acción o unas acciones distintas, pero no se dan porque el personaje sigue irónicamente en su misma línea (Bergson 185). El personaje permanece inflexible, gobernado por una estructura mental rígida, condenado a la repetición perpetua y convertido por tanto en objeto de mofa. Todo

\footnotetext{
${ }^{10} \mathrm{El}$ concepto del humor como "arma" subversiva en contra del opresor aparece en numerosos estudios críticos acerca del tema, sobre todo en la crítica feminista sobre el humor de otras literaturas (Barreca 30). Me dejo llevar, sin embargo, por los planteamiento hechos al respecto por Emir Rodríguez Monegal (3) y José Miguel Oviedo (35) en sus respectivos estudios acerca del humor en la literatura hispanoamericana.
} 
esto nos lleva a nuestra observación anterior: la burla va tanto para la mujer como para el hombre; ella por ser cómplice de la explotación de su propio grupo y por su incapacidad para transgredir las reglas, y él por una notable ignorancia y tontería que lo llevan a ser víctima de su propia trampa. En última instancia, hacia allí va precisamente dirigida la crítica, hacia la encubierta trampa, especie de emboscada planificada por el hombre y encaminada a convertir a las mujeres en espectáculos de si mismas.

Ocampo, por otro lado, al igual que en "La música de la lluvia", además de criticar el interés trivial de la sociedad burguesa por lo superficial en un mundo de apariencias, parodia otro discurso conocido: el romance popular entrelazado con el melodrama folletinesco. Sklodowska señala acertadamente que "en la escritura femenina el desafío deriva del mero cambio del sujeto hablante” (145). Más adelante añade “que la especificidad de la escritura femenina consiste en su actitud ambivalente con respecto a la tradición: una actitud esencialmente paródica que tiene que abrazar los valores del discurso patriarcal para luego subvertirlos” (146). La subversión en "Los celosos” se da cuando el discurso melodramático es representado por el marido y no por su mujer. La afectación del discurso del intertexto, con sus consabidos clichés, se apodera exclusivamente del protagonista masculino: "Me casaré con una rubia de pestañas oscuras como la noche y de ojos celestes como el cielo de un día de primavera” (123). Ese ideal poético ensoñador (invertido irónicamente en la realidad) va a estar acompañado de expresiones y clichés fácilmente reconocibles que parodian constantemente el texto en cuestión: “¿Cuándo oiré tu voz melodiosa, deidad de mis sueños?”; “Y ese collar de perlas que se entrevé cuando sonreís, es lo más peligroso de todo” (126). La ironía implícita en el discurso narrativo al igual que la mezcla incongruente entre lo poético y lo ridículo, privan al tema de toda solemnidad y lo remiten a la burla y al juego paródico. Pese a ello, la inusual adopción de la tradición melodramática folletinesca por parte del marido no sorprende del todo al lector, por el contrario, explica y justifica su marcada enajenación y quijotismo. En otras palabras, la saturación y asimilación del intertexto en el carácter y comportamiento del marido no le permiten ver más allá de las coordenadas que autolimitan el género parodiado, así como tampoco Don Quijote, inmerso como estaba en su atiborrado mundo de novelas de caballería, fue incapaz de distinguir del todo entre su idealizada Dulcinea del Toboso y la simple labradora Aldonza Lorenzo.

\section{ConClusión}

Podemos confirmar que el humor mordaz y burlesco en los cuentos examinados se alimenta de varias vertientes o estrategias: la deformación caricaturesca, la ironía, la hipérbole, la inversión, los juegos desenmascaradores y la parodia de fórmulas codificadas. Los relatos en cuestión son satíricos en tanto despliegan continuamente una mirada (blanco de ataque) extratextual y despiadadamente crítica hacia esa moral pequeñoburguesa y sus vicios. La desmitificación de la ideología burguesa (en algunos casos también machista) expone un comportamiento social interpretado como ridículo, hilarante, una farsa regida por el fingimiento. La embestida irá dirigida precisamente hacia esos personajes/marionetas que enredados en sus propios cordeles irán tropezando y tambaleando 
hasta caer desenfrenadamente en la caricatura burlesca, caricatura que pretende desenmascarar y señalar la catarata de estereotipos generados.

\section{BiBLIOGRAFÍA}

Araújo, Helena. “Erotismo y perversión en un cuento de Silvina Ocampo”. Río de la Plata 1 (1985): 141-45.

Balderston, Daniel. "Los cuentos crueles de Silvina Ocampo y Juan Rodolfo Wilcock”. Revista Iberoamericana XLIX/125 (octubre-diciembre 1983): 743-52.

Barreca, Regina. "Untamed and Unabashed: Towards a Theory of Women and Humor in Literature". Untamed and Unabashed. Essays on Women and Humor in British Literature. Detroit: Wayne State University Press, 1994. 11-33.

Bergson, Henri. Laughter: An Essay on the Meaning of the Comic. Cloudesley Brereton y Fred Rothwell, trads. New York: Macmillan, 1911.

Booth, Wayne C. A Rhetoric of Irony. Chicago: University of Chicago Press, 1974.

Ferreira-Pinto, Cristina. “El narrador intimista de Silvina Ocampo: 'La continuación’”. Revista de Estudios Hispánicos 17-18 (1990-91): 309-15.

Fox-Lockert, Lucia. “Silvina Ocampo’s Fantastic Short Stories”. Monographic Review/ Revista Monográfica 4 (1988): 221-29.

Hutcheon, Linda. A Theory of Parody: The Teachings of Twentieth Century Art Forms. New York: Methuen, 1985.

Klingenberg, Patricia N. Fantasies of the Feminine. The Short Stories of Silvina Ocampo. Lewisburg, PA: Bucknell University Press, 1999.

Koestler, Arthur. The Act of Creation. London: Hutchinson and Co., 1969.

Meehan, Thomas C. "Los niños perversos en los cuentos de Silvina Ocampo”. Essays on Argentine Narrators. Thomas Meehan, ed. Chapel Hill: Albatros Hispanófila, 1982. 31-44.

Molloy, Silvia. "Simplicidad inquietante en los relatos de Silvina Ocampo”. Lexis 2/2 (diciembre 1978): 241-51.

Ocampo, Silvina. Cornelia frente al espejo. Barcelona: Tusquets, 1988. Y así sucesivamente. Barcelona: Tusquets, 1987.

La furia y otros cuentos. [1959]. Madrid: Alianza, 1982. Los días de la noche. Buenos Aires: Sudamericana, 1970. Las invitadas. Buenos Aires: Losada, 1961.

Oviedo, José Miguel. “Laughing is a Serious Matter”. Review: Latin American Literature and Arts 35 (July-December 1885): 7-9.

Pirandello, Liugi. Ensayos. José Miguel Velloso, trad. Madrid: Guadarrama, 1968.

Rodríguez Monegal, Emir. “Tradition of Laughter”. Review: Latin American Literature and Arts 35 (July-December 1885): 3-6.

Sklodowska, Elzbieta. La parodia en la nueva novela hispanoamericana (1960-1985). Amsterdam/Philadelphia: John Benjamins Publishing Company, 1991.

Test, George A. Satire: Spirit and Art. Tampa: University of South Florida Press, 1991. Tomassini, Graciela. El espejo de Cornelia: La obra cuentística de Silvina Ocampo. Buenos Aires: Plus Ultra, 1995. 
Ulla, Noemí. Encuentros con Silvina Ocampo. Buenos Aires: Belgrano, 1982. 